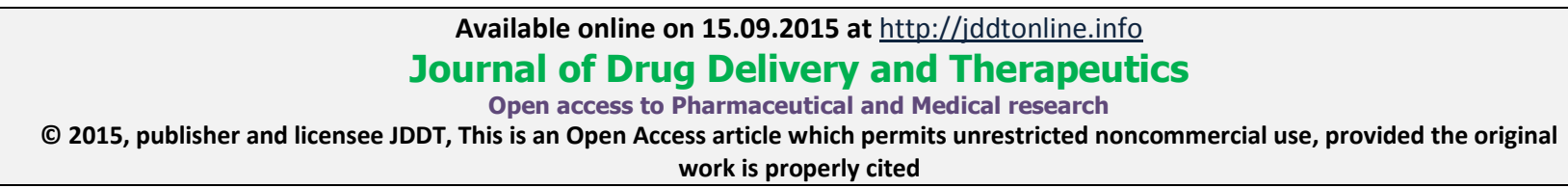

\title{
REDUCTION OF ACRYLAMIDE FORMATION IN POTATO CHIPS BY AQUEOUS EXTRACT OF ROSELLE
}

\author{
El-Desouky T. A.*, May M. Amer and Lamyaa EL-Sedeek \\ Food Toxicology and Contaminants Dept. National Research Centre., Dokki, Cairo, Egypt \\ *Corresponding Author's e-mail: eldesoukyt@yahoo.com \& tarekeldesouky6@gmail.com
}

Received 06 July 2015; Review Completed 29 July 2015; Accepted 09 August 2015, Available online 15 Sep 2015

\begin{abstract}
Acrylamide (AA) is an industrial chemical formed in some foods; particularly starchy foods, during heating process such as frying, baking and roasting. AA is proven to be carcinogenic in animals and a probable human carcinogen formed in foods by the reaction of free amino acid with reducing sugars as part of the Maillard reaction during heating under high temperature and low moisture conditions. Therefore, the aim of this study was to use aqueous extract of roselle as a natural source of antioxidants to reduce AA formed in potato chips. The results showed that the percentages of reduction of AA were $10.1 \%$ and $12.92 \%$ in samples that were treated with $1 \%$ of aqueous extract of roselle and soaked at 10 and 20 mins respectively. There was observed increase in AA reduction by it was $75.41 \%$ and $82.46 \%$ after soaking at 10 and 20 mins respectively with $5 \%$ extract. Conclusively, the aqueous extract of roselle is effective in reducing the AA formed in potato chips due as it contains of antioxidant compounds.
\end{abstract}

Keywords: acrylamide (AA), potato, roselle, soaking and reduction

\section{INTRODUCTION}

Acrylamide (AA) was classified as a Group 2A carcinogen by the International Agency for Research on Cancer ${ }^{1}$ and a Category 2 carcinogen and Category 2 mutagen by the European Union 2, which caused worldwide concern ${ }^{3}$. AA was found to occur during the frying, grilling or baking of foods via the Maillard reaction of reducing sugars with asparagine at temperatures above $120{ }^{\circ} \mathrm{C}$ and under low moisture conditions ${ }^{4-7}$ as show in (Fig 1). AA formation depends upon many factors, such as the amount of reducing sugars and free asparagine, the cooking process, including the temperature and the time, the $\mathrm{pH}$ and the surface-to-volume ratio of the food materials ${ }^{8-9}$. In addition to the exogenous factors affecting AA formation, the endogenous factors include the presence of precursors in the food, is indispensable for AA formation. These precursors include amino acids (such as free asparagine, alanine, arginine, aspartic acid, cysteine, glutamine, methionine, threonine, and valine) and mono- or disaccharides (such as reducing sugar glucose and fructose and non-reducing sugar sucrose), the levels of which depends largely on genetic and environmental factors. Thus, species and cultivars of food raw materials, farming systems, time of harvest, and storage time and temperature, all may impact the final levels of the precursors to AA to some degree ${ }^{10-}$ 12. Previos estudies on AA have mostly concentrated on carbohydrate-rich foods such as French fries, bread, potato crisps and biscuits as well as coffee. Potato products have the highest AA content among these foodstuffs ${ }^{13}$. The potato is one of the most important vegetable with respect to its value of production and nutritional impact. Potatoes have considerable amounts of these precursors and therefore, fried potato products, such as French fries and chips, have been found to contain high levels of acrylamide ${ }^{14-15}$. AA was formed in French fries and potato chips heated above $120{ }^{\circ} \mathrm{C}$. These two products exhibited relatively high values of acrylamide of $424 \mathrm{mg} / \mathrm{kg}$ and $1739 \mathrm{mg} / \mathrm{kg}$, respectively 5 . Previous studies found that many exogenous and endogenous factors play important roles in the formation of $\mathrm{AA}$, so different strategies and methods have been developed to mitigate AA in food successfully. Antioxidants affect AA mitigation significantly by abstracting reactive free electrons from free radical intermediates produced in the Maillard reaction. Friedman and Levin, 2008 reported that antioxidants present in bamboo leaves and other plants including tea significantly reduce AA formation in heated foods. On the other hand the addition of aqueous rosemary extract, rosemary oil or dried rosemary leaves to wheat dough reduces the content of $\mathrm{AA}$ in wheat buns by $62 \%, 67 \%$ and $57 \%$, respectively ${ }^{16}$. Also plant extracts of mint, cumin seeds and star anise cause the greatest AA reductions by $75 \%, 73 \%$ and $69 \%$, respectively ${ }^{17}$. Soaking of potato crisps in acetic acid 
solution for 60 mins at $20^{\circ} \mathrm{C}$ prior to frying results in a $90 \%$ decrease in AA level ${ }^{18}$.

Hibiscus sabdariffa L. (family: Malvacea) is an annual herb shrub popularly known as Roselle (English) and Karkadeh (Arabic). On the other hand the plant is widely cultivated in tropical and subtropical countries. The petals of the roselle used in many medicinal applications to cure liver damage, hypertension and leukemia ${ }^{19-20}$. In addition the petals extract of the plant is rich in flavonoids and natural colorants, which include anthocyanins and catechins. Many phenolic compounds found in roselle extract, in which hibiscus acid, hydroxycitric acid, chlorogenic acid, delphinidin 3-sambubioside, cyaniding 3-sambubioside and 7hydroxycoumarin were the major components. Also the extract of roselle was rich in ascorbic acids and acid polysaccharides ${ }^{21-22}$. Two predominant anthocyanin compounds (delphinidin3-sambubioside and cyanidin 3sambubioside) and two minor compounds (cyanidin 3glucoside and delphinidin 3-glucoside) were found in the aqueous extract of roselle ${ }^{23-24}$. In addition Maganha et al 25 reported that delphinidin, delphinidin 3glucoxyloside, delphinidin 3-monoglucoside and cyanidin 3,5-diglucoside were the major anthocyanins in roselle. Therefore, the objective of this study was to use aqueous extract of roselle as a natural source of antioxidants to reduce AA formed in potato chips.

\section{MATERIALS AND METHODS}

\subsection{Material}

The flowers of Roselle was purchased from a local market, Cairo, Egypt and then ground with blender (2000 rpm) to obtain fine powder. Sunflower oil was purchased from local market.

\subsection{Reagents and Solutions}

AA (purity > 99.9\%) was purchased from (Darmstadt, Germany). All solvents were of High Performance Liquid Chromatography (HPLC) grade. The water was double distilled with Millipore water purification system (Bedford, M A, USA).

\subsection{Methods}

\subsubsection{Preparation of extract}

Ten grams of the fine powder of roselle was mixed with $100 \mathrm{ml}$ of water at room temperature for $24 \mathrm{~h}$, then the extract was filtered through filter papers and then, re-filtered through a nitro-cellulose paper $(\varnothing=0.45$ $\mu \mathrm{m})$. Final extract was kept in a dark bottle in refrigerator at $4{ }^{\circ} \mathrm{C}$ until use.

\subsubsection{Determination of total phenolic content}

The total phenolic content was determined according to the Folin-Ciocalteu procedure Zilic et al [26]. Briefly, the extract $(100 \mu \mathrm{l})$ was transferred into a test tube and the volume adjusted to $500 \mu \mathrm{l}$ with distilled water and oxidized with the addition of $250 \mu \mathrm{l}$ of Folin-Ciocalteau reagent. After $5 \mathrm{~min}$, the mixture was neutralized with $1.25 \mathrm{ml}$ of $20 \%$ aqueous $\mathrm{Na}_{2} \mathrm{CO}_{3}$ solution. After 40 min, the absorbance was measured at $725 \mathrm{~nm}$ against the solvent blank. The total phenolic content was deter- mined by means of a calibration curve prepared with gallic acid, expressed as $\mu \mathrm{g}$ of gallic acid equivalent (GAE) per $\mathrm{g}$ of sample.

\subsubsection{Analysis of total flavonoid content}

The total flavonoid content was determined according to Zilic et al. ${ }^{26}$. Briefly, $50 \mu$ l of $5 \%$ NaNO2 was mixed with $100 \mu \mathrm{l}$ of extract. After $6 \mathrm{~min}, 500 \mu \mathrm{l}$ of a $10 \%$ $\mathrm{AlCl} 3$ solution was added. After $7 \mathrm{~min}, 250 \mu \mathrm{l}$ of $1 \mathrm{M}$ $\mathrm{NaOH}$ was added, and the mixture was centrifuged at $5000 \mathrm{~g}$ for $10 \mathrm{~min}$. Absorbance of the supernatant was measured at $510 \mathrm{~nm}$ against the solvent blank. The total flavonoid content was expressed as $\mu \mathrm{g}$ of catechin equivalent (CE) per $\mathrm{g}$ of sample.

\subsubsection{Determination of antioxidant activity:}

\section{Determination of radical DPPH scavenging activity}

Free radical scavenging capacity of the Moringa peel extract was determined using the stable 1,1-Diphenyl-2picryl-hydrazyl (DPPH•) according to Hwang and Do $\mathrm{Thi}^{27}$. The final concentration was $200 \mu \mathrm{M}$ for DPPH• and the final reaction volume was $3.0 \mathrm{ml}$. The absorbance at $517 \mathrm{~nm}$ was measured against a blank of pure methanol at $60 \mathrm{~min}$. Percent inhibition of the DPPH free radical was calculated by the following equation:

$$
\text { Inhibition }(\%)=\{(\text { A control }-\mathrm{A} \text { sample }) / \mathrm{A} \text { control }\} \mathrm{X}
$$

Where: A control is the absorbance of the control reaction (containing all reagents except the test compound).

A sample is the absorbance with the test compound.

\subsubsection{Preparation of potatoes chips:}

Potatoes (Solanum tuberosum L.), were washed and after peeling, slices with a thickness of $1.5 \mathrm{~mm}$ were prepared by using a mechanical slicer (Italimport SRL, Model 90915, China). Before frying; the slices were soaked in mix of distilled water which treated by extract of Roselle at levels of 1, 2, 3, 4 and 5\% for exactly 10 and $20 \mathrm{~min}$ at room temperature $\left(25-28^{\circ} \mathrm{C}\right) .200 \mathrm{~g}$ of slices were fried in an electric deep fryer with a capacity of $3 \mathrm{Lit}$ of oil at $170^{\circ} \mathrm{C}$ for 3-4 min. Directly after frying, the crisps were cooled on an absorbing paper. A part of the batch was homogenized for acrylamide analysis, while another part was used for sensory valuation.

\subsubsection{Standard solutions}

The standard solutions of AA were prepared according to a method described by Khoshnam et al ${ }^{28}$. Stock solution of AA $(1000 \mu \mathrm{g} / \mathrm{ml})$ was prepared by dissolving $0.1 \mathrm{~g}$ of AA in deionized water and diluted to $100 \mathrm{ml}$ in a volumetric flask. The successive $100 \mu \mathrm{g} / \mathrm{ml}$ and $2 \mu \mathrm{g} / \mathrm{ml}$ stock solutions of AA were prepared from this solution. Working standard solutions of AA (20, 40, $80,160,240,320$ and $400 \mathrm{ng} / \mathrm{ml}$ ) were prepared by appropriate dilution of $2 \mu \mathrm{g} / \mathrm{ml}$ stock solution with water. All standard solutions were protected from the light, and stored in a refrigerator at $4{ }^{\circ} \mathrm{C}$. 


\subsubsection{Determination of acrylamide}

High Performance Liquid Chromatography (HPLC) system (Waters) equipped with model 600 delivery system (Water), UV detector and the data were integrated and recorded by millennium chromatography manger software 210 (Waters, Milford MA 0175). Reverse phase hyper clone $5 \mu$ ODS C18 column (2.5 $\mathrm{mm}$ X $30 \mathrm{~cm}$ ).

The extraction and determination of acrylamide was according to Khoshnam et al ${ }^{28}$. Ground and homogenized chips $(4.0 \mathrm{~g})$ were weighed into a closed flask, defatted twice by adding $10 \mathrm{ml}$ hexane and shaking for $5 \mathrm{~min}$. The mixture was dried under vacuum, after decantation. AA was extracted by addition of $20 \mathrm{ml}$ of acetone and $100 \mu \mathrm{l}$ of water to the defatted sample. The flask was placed in an ultrasonic bath at $40{ }^{\circ} \mathrm{C}$ for about $20 \mathrm{~min}$. The acetone was filtered through a filter paper. To dryness $10 \mathrm{ml}$ of the filtrate was evaporated gently under vacuum. Then, $2 \mathrm{ml}$ of water was added and shaken thoroughly to dissolve the residue. The aqueous solution was filtered through a filter paper and injected to the column using a $20 \mu \mathrm{l}$ injection loop. Flow rate was $0.15 \mathrm{ml} / \mathrm{min}$ and the column temperature was kept constant at $40^{\circ} \mathrm{C}$. The analysis was performed at $202 \mathrm{~nm}$ with a UV detector. AA concentrations in treated samples were determined from the standard curve, using peak area for quantitation.

\subsubsection{Sensory evaluation and statistical analysis}

Ten randomized volunteers were invited to score samples (30 min after frying) from the control and test groups in terms of color, flavor, texture and overall acceptability according to Zhang and Zhang ${ }^{12}$

\subsection{Statistical analysis}

All data were statistically analyzed using the General Linear Model of the SPSS var. 19. The significance of the differences treatment was determined by WallerDuncan k-ratio (Waller and Duncan 1969). All statements of significance were based on probability of $\mathrm{p}<0.05$.

\section{RESULTS AND DISCUSSION}

\subsection{Total phenolics and flavonoids contents in aqueous extract of roselle}

The total phenols content of roselle flowers and total flavonoids were presented in Table (1). The results obtained in this study showed that content of total phenols and total flavonoids were $18.5 \mathrm{mg} \mathrm{GAE} / \mathrm{ml}$ and $36.32 \mathrm{mg} \mathrm{CE} / \mathrm{ml}$, respectively. On the other hand the antioxidant activity amounted to $78.3 \%$ in the determination of radical DPPH scavenging activity. These results are in agreement with the available literature ${ }^{29-31}$. The results indicated that aqueous extract of flowers roselle was good source for natural antioxidant, phenols and flavonoids have been found to be helpful in protection and prevention against many degenerative diseases and pathological processes such as in ageing degenerative diseases, coronary heart disease. Obouayeba et al. ${ }^{32}$ reported that the high antioxidant activity observed with extracts of petals in roselle would be linked to the presence of polyphenolic compounds such as phenolic acids, flavonoids and anthocyanins.

Table 1. Concentration of total phenols and flavonoids in aqueous extract of roselle.

\begin{tabular}{|c|c|c|c|}
\hline Aqueous extract & $\begin{array}{c}\text { Total phenols } \\
(\mathrm{mg} \mathrm{GAE} / \mathrm{mL})\end{array}$ & $\begin{array}{c}\text { Total flavonoids } \\
(\mathrm{mg} \mathrm{CE} / \mathrm{mL})\end{array}$ & $\begin{array}{c}\text { Antioxidant } \\
\text { activity }(\%)\end{array}$ \\
\hline Roselle & 18.5 & 36.32 & 78.3 \\
\hline
\end{tabular}

\subsection{Effect of aqueous extract of roselle on formed of AA in potato chips}

Data presented in Table (2) showed content of AA in potato chips made of slices were soaked in mix of distilled water which treated by extract of roselle at levels of 1,2,3,4 and 5\% for exactly 10 and $20 \mathrm{~min}$. The lowest AA content was found in sample treated by $5 \%$ from of aqueous extract roselle for $20 \mathrm{~min}$. The results indicated that content of AA in control sample (without treated) was $32.17 \pm 1.8 \mu \mathrm{g} / \mathrm{kg}$. While observed decrease in formation of AA in samples were treated with extract of roselle. The content of AA in treated samples by $5 \%$ from extract which soaked at 10 and 20 min was degraded to $7.91 \pm 0.95$ and $5.64 \pm 0.43 \mu \mathrm{g} / \mathrm{kg}$, respectively compared with control samples. The analysis of variance summarized in Table (3) showed higher significant differences between the content of AA in samples after treated with different levels of extract. These results clearly indicated that the soaking time higher significantly than the levels of extract. 
Table 2. Content of AA in potato chips made of slices were soaked with difference levels aqueous extract of roselle for 10 and $20 \mathrm{~min}$ (mean values $\pm \mathrm{SE}$ )

\begin{tabular}{|c|c|c|}
\hline Concentrations of aqueous extract* & $\begin{array}{c}\text { Content of AA } \\
(\mu \mathrm{g} / \mathrm{kg}) \\
(10 \mathrm{~min})\end{array}$ & $\begin{array}{c}\text { Content of AA } \\
(\mu \mathrm{g} / \mathrm{kg}) \\
(20 \mathrm{~min})\end{array}$ \\
\hline Control (without treated) & $32.17 \pm 1.8^{\mathrm{a}}$ & $32.17 \pm 1.8^{\mathrm{a}}$ \\
\hline $1 \%$ & $28.92 \pm 1.04^{\mathrm{ab}}$ & $28.01 \pm 0.81^{\mathrm{b}}$ \\
\hline $2 \%$ & $26.55 \pm 0.48^{\mathrm{b}}$ & $23.46 \pm 0.64^{\mathrm{c}}$ \\
\hline $3 \%$ & $21.28 \pm 1.02^{\mathrm{c}}$ & $16.8 \pm 0.96^{\mathrm{d}}$ \\
\hline $4 \%$ & $13.67 \pm 0.5^{\mathrm{d}}$ & $10.13 \pm 0.63^{\mathrm{f}}$ \\
\hline $5 \%$ & $7.91 \pm 0.95^{\mathrm{f}}$ & $5.64 \pm 0.43^{\mathrm{g}}$ \\
\hline
\end{tabular}

* 100ml distilled water was mixed with $1,2,3,4$ and $5 \mathrm{ml}$ extract of roselle

Mean values in the same column with the same letter are not significant different at $p \leq 0.05$.

Table 3. Analysis of variance of the effect of aqueous extract of roselle and time soaking on content of AA in samples treated and control.

\begin{tabular}{|c|c|c|c|c|c|}
\hline Source & SS & df & MS & F & P \\
\hline Intercept & 12654.923 & 1 & 12654.923 & 4950.690 & 0.000000 \\
\hline Extract & 2326.782 & 5 & 465.356 & 182.050 & 0.000000 \\
\hline Time & 61.204 & 1 & 61.204 & 23.943 & 0.000000 \\
\hline extract*time & 10.944 & 4 & 2.736 & 1.070 & 0.395 \\
\hline Error & 56.236 & 22 & 2.556 & & \\
\hline Total & 15150.912 & 33 & & & \\
\hline
\end{tabular}

SS: Sum of Squares, df: degree of freedom, MS: mean square, P: probability at confidence 0.95 .

Data presented in Fig (2) showed the percentage of reduction of formation $\mathrm{AA}$ in potato chips made of slices were soaked at 10 and $20 \mathrm{~min}$ with differences levels from aqueous extract of roselle. The results showed reduction of AA were 10.1 and $12.92 \%$ in samples were treated by $1 \%$ from extract and soaked at 10 and $20 \mathrm{~min}$, respectively, while observed increase on reduction with $5 \%$ extract; it was 75.41 and $82.46 \%$ after soaking at 10 and $20 \mathrm{~min}$, respectively.

Reduction of AA formed may be due to flavonoids react with AA precursors or key intermediates during AA formation. Some study reported that the addition of a flavonoid-rich spice mix could effectively reduce AA levels by up to $50 \%$ in potato chips. For example, Cheng et al. ${ }^{33}$ found that naringenin, a characteristic compound of flavanones, could scavenge the amino source asparagine-derived intermediates at positions 6 and 8 of the A-ring in its flavonoid structure and divert them from the pathways leading to acrylamide formation. As it is well known that the reducing sugars one of the important components that interference in the formation of acrylamide so in the current study we have reduced sugars by soaking at 10 and $20 \mathrm{~min}$. This proposal confirms by Pedreschi et al ${ }^{11}$ reported that the levels of reducing sugars can be lowered by soaking the cut potatoes in water at room temperature before they are fried. AA formation was higher in the control sample than treated samples suggesting that the soaking process with aqueous extract of roselle leads to a higher leaching of one important acrylamide precursor, such as glucose, that finally results in lower AA formation.

On the other hand, natural antioxidant compounds present in the aqueous extract of roselle has been found effective to decreasing AA formation due to three effects: 1) radical scavenging activity, 2) carbonyl trapping effect and 3) limitation of sugar degradation through the Maillard reaction

\subsection{Sensory evaluation}

The results of sensory evaluation of potato chips made of sclices were treated with aqueous extract of roselle are shown in Table (4). The different treatments did not affect on taste, odor, texture and overall acceptability. While the results showed significant differences in color between the samples as compared with control sample (Fig 3). Samples treated with 5\% aqueous extract of roselle has lowest scores of color $(6.9 \pm 1.01)$ and overall acceptability $(7.93 \pm 0.62)$. The scores of taste were between 8.67 and 7.95 in samples treated with 1 and 5\% of extract, respectively. On the other hand the results showed that the addition of aqueous extract of roselle did not changed significant in score of overall acceptability between control samples (8.27) and samples treated by 5 $\%(7.93)$. 
Table 4. Sensory evaluations of potato chips made of slices were treated with differences levels aqueous extract of roselle. (Scores mean values $\pm \mathrm{SD}$ )

\begin{tabular}{|c|c|c|c|c|c|c|}
\hline \multirow{2}{*}{ Characteristics** $^{*}$} & \multicolumn{7}{|c|}{ Treated samples* $^{*}$} \\
\cline { 2 - 7 } & Control & $\mathbf{1 \%}$ & $\mathbf{2 \%}$ & $\mathbf{3 \%}$ & $\mathbf{4 \%}^{\mathbf{5 \%}}$ & $\mathbf{5 \%}$ \\
\hline Taste (10) & $8.77 \pm 1.25^{\mathrm{a}}$ & $8.67 \pm 1.09^{\mathrm{a}}$ & $8.49 \pm 1.06^{\mathrm{a}}$ & $8.42 \pm 1.08^{\mathrm{a}}$ & $8.34 \pm 1.09^{\mathrm{a}}$ & $7.95 \pm 1.14^{\mathrm{a}}$ \\
\hline Color (10) & $8.5 \pm 0.71^{\mathrm{a}}$ & $7.6 \pm 0.54^{\mathrm{abc}}$ & $7.7 \pm 0.88^{\mathrm{bc}}$ & $8.06 \pm 0.47^{\mathrm{cd}}$ & $7.27 \pm 0.96^{\mathrm{ab}}$ & $6.9 \pm 1.01^{\mathrm{a}}$ \\
\hline Odor (10) & $8.45 \pm 0.78^{\mathrm{a}}$ & $8.35 \pm 0.98^{\mathrm{a}}$ & $8.43 \pm 0.76^{\mathrm{a}}$ & $7.8 \pm 0.85^{\mathrm{a}}$ & $7.87 \pm 0.86^{\mathrm{a}}$ & $7.64 \pm 1.17^{\mathrm{a}}$ \\
\hline Texture (10) & $8.2 \pm 0.57^{\mathrm{a}}$ & $7.87 \pm 0.66^{\mathrm{a}}$ & $7.75 \pm 0.75^{\mathrm{a}}$ & $7.8 \pm 0.74^{\mathrm{a}}$ & $7.8 \pm 0.65^{\mathrm{a}}$ & $7.65 \pm 0.76^{\mathrm{a}}$ \\
\hline $\begin{array}{c}\text { Overall } \\
\text { acceptability (10) }\end{array}$ & $8.27 \pm 0.47^{\mathrm{a}}$ & $8.11 \pm 0.53^{\mathrm{a}}$ & $8.15 \pm 0.77^{\mathrm{a}}$ & $7.95 \pm 0.82^{\mathrm{a}}$ & $8.26 \pm 0.68^{\mathrm{a}}$ & $7.93 \pm 0.62^{\mathrm{a}}$ \\
\hline
\end{tabular}

- $\quad$ Any two values not followed by the same letters are significantly different at $5 \%$ level.

In this study, color high scores were recorded for treated samples with low acrylamide content comparing to the control. However, no correlation was found between browning and the acrylamide content in potato crisps according to [34-35]. Sensory evaluation results showed that the flavor and texture of fried bread sticks processed by antioxidant of bamboo leaves and extract of green tea had no significant difference compared to normal food matrixes [36] (Haase et al. 2003). Finally the results clearly showed the influence of non-sensory evaluation as a result of the treatment by aqueous extracts of roselle, most measurements were not significant.

\section{CONCLUSIONS}

It could be concluded that the aqueous extract of roselle is a good source of many of the active compounds such as phenolics and flavonoids. On the other hand the current study indicated that the antioxidants found in aqueous extract of roselle could reduce the acrylamide content in potato chips.

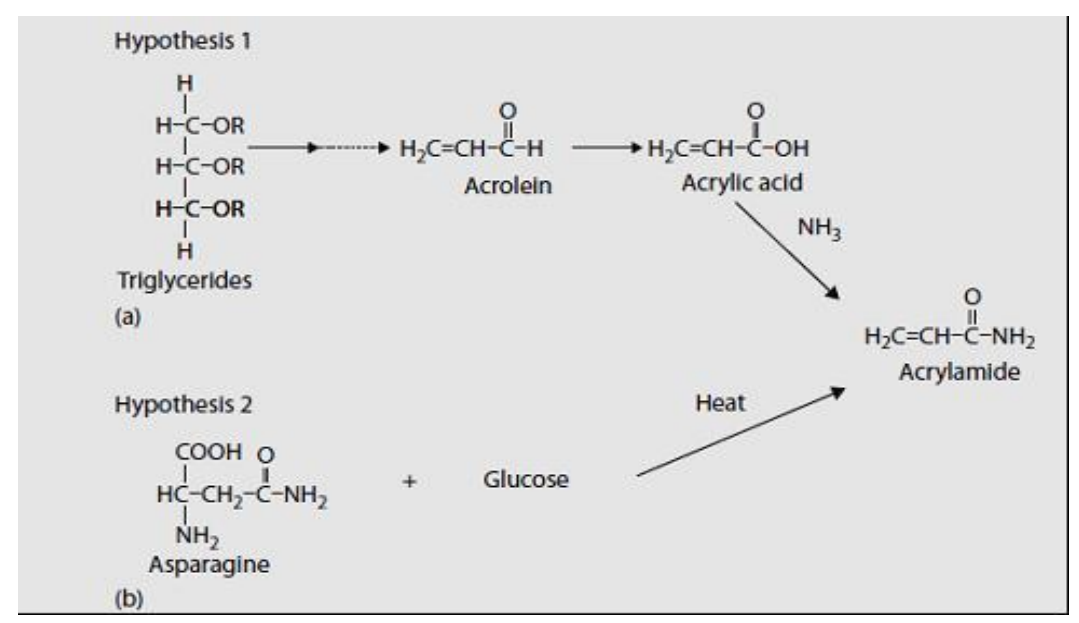

Figure 1. Possible routes of formation of acrylamide according to Becalski et al. 2003

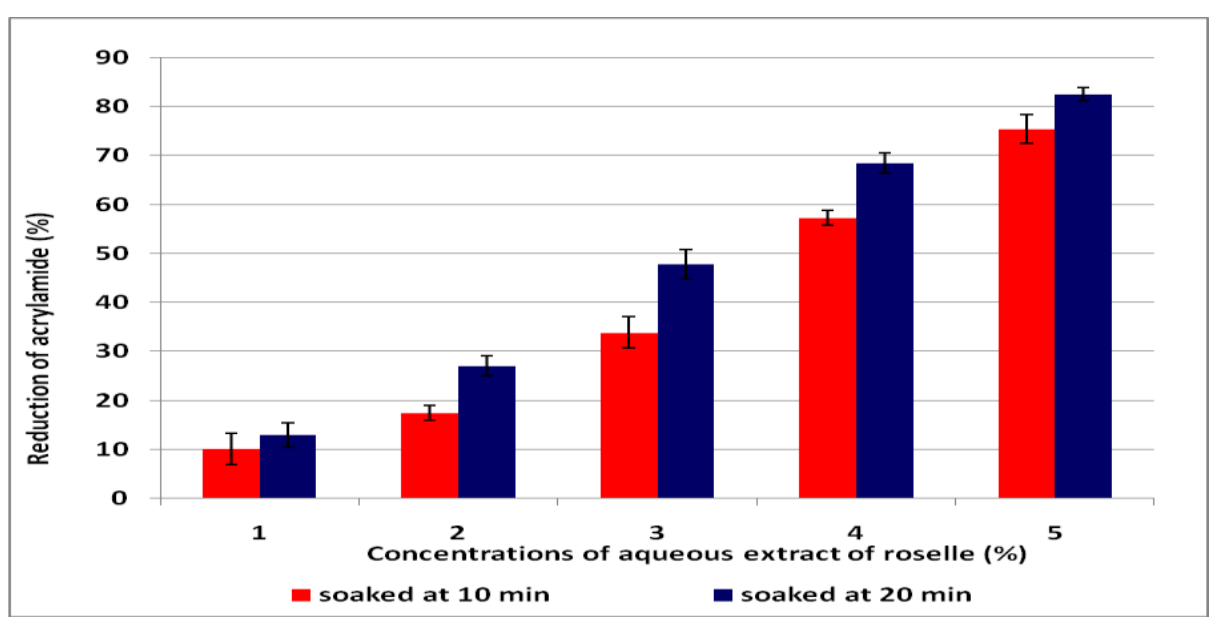

Figure 2: The percentage of reduction of AA in potato chips made of slices were soaked at 10 and 20 min with aqueous extract of roselle 


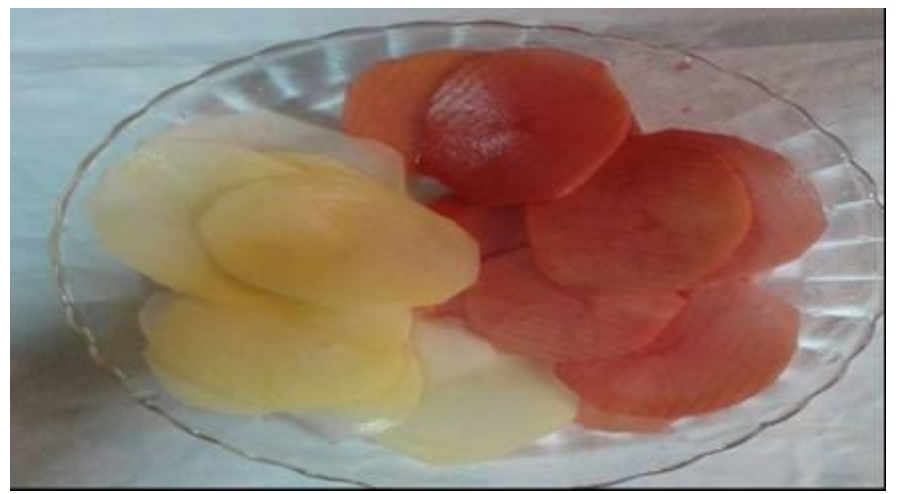

Figure 3: Potato chips after treatment with aqueous extract of roselle and control.

\section{REFERENCES}

[1] IARC, 1994. Monographs on the evaluation of carcinogenic risks to humans, 60, 389. ECFA, 2011. Safety evaluation of certain contaminants in food. Acryl amide. In: 72nd meeting of the Joint FAO/WHO Expert Committee on Food Additives (JECFA), FAO JECFA Monograph 8, p1-151.

[2] EC, 2002. Opinion of the scientific committee on food on new findings regarding the presence of acrylamide in food. European Commission, Belgium.

[3] FAO/WHO. 2002. Consultation on the health implications of acrylamide in food. Geneva, 25-27.

[4] Erdoğdu S B, Palazoğlu T K, Gökmen V, Şenyuva H Z, Ekiz Hİ. 2007. Reduction of acrylamide formation of French fries by microwave pre-cooking of potato strips. J. of the Scie. of Foo. and Agricu.87, 133-137.

[5] Zyzak DV, Sanders RA, Stojanovic M, Tallmadge DH, Eberhardt BL, Ewald Dl. 2003. Acrylamide formation mechanism in heated foods. J. of Agricul. and Food Chem. 51, 4782-4787.

[6] Mottram, D. S., Wedzicha, B.L., \& Dodson, A. T. 2002. Acrylamide is formed in the Maillard reaction. Nature, 419, 448-449.

[7] Stadler RH, Blank I, Varga N, Robert F, Hau J, Guy PA. 2002. Acrylamide from Maillard reaction products. Natur. 419, 449-450.

[8] Friedman M. 2003. Chemistry, biochemistry, and safety of acrylamide. A revi. J. of Agricul. and Foo. Chem. 51, 4504 4526

[9] Rydberg P, Eriksson S, Tareke E, Karlsson P, Ehrenberg L, Trnqvist M. 2003. Investigations of factors that influence the acrylamide content of heated foodstuff. J. of Agricul. Food Chem. 51, 7012-7018.

[10] Halford NG, Curtis TY, Muttucumaru N, Postles J, Elmore JS, Mottram DS. 2012. The acrylamide problem: a plant and agronomic science issue. J. Exp. Bot. 63, 2841-2851.

[11] Pedreschi F, Maria SM, Kit G. 2014. Current issues in dietary acrylamide: formation, mitigation and risk assessment. $J$. Sci. Food Agric. 15, 9-12.

[12] Zhang, Y. and Zhang, Y. 2007. Formation and reduction of acrylamide in Maillard reaction: a review based on the current state of knowledge. Crit. Rev. Food Sci.47, 521-542.

[13] Gökmen V, Şenyuva H Z, Acar J, Sarığlu K. 2005. Determination of acrylamide in potato chips and crisps by high-performance liquid chromatography. J. of Chrom. A, 1088, 193-199.

[14] Lineback DR, Coughlin JR, Stadler RH. 2012. Acrylamide in foods: A review of the science and future considerations. Annu. Rev. of Food. Scie. and Tech. 3, 15-35.

[15] Medeiros Vinci R, Mestdagh F, De Meulenaer B. 2012. Acrylamide formation in fried potato products - Present and future, a critical review on mitigation strategies. Food Chem. $15,1138-1154$
[16] Zhang Y, Zhang Y. 2008. Study on reduction of acrylamide in fried bread sticks by addition of antioxidant of bamboo leaves and extract of green tea. Asia Pac J Clin Nutr. 16(1 1): 131-136.

[17] Zhu F, Cai YZ, Ke J, Corke H. 2009. Evaluation of the effect of plant extracts and phenolic compounds onreduction of acrylamide inan asparagine/glucosemodel system by RPHPLC-DAD. Journal of the Science of Food and Agriculture, 89, 1674-1681.

[18] Kita A, Brathen E, Knutsen S, Wickl und T. (2004). Effective ways of decreasing acrylamide content in potato crisps during processing. Journal of Agricultural and Food chemistry, 52 (23), 7011-7016.

[19] Ochani PC, D'Mello P. 2009. Antioxidant and antihyperlipidemic activity of Hibiscus sabdariffa Linn. Leaves and calyces extracts in rats. Indian J. Exp. Biol. 47, 276-282.

[20] Chen J, Wang C, Wang C, Sheu J, Lin C, Lin H. 2013. Hibiscus sabdariffa leaf polyphenolic extract inhibits LDL oxidation and foam cell formation involving up-regulation of LXR $\alpha /$ ABCA1 pathway. Food Chem. 141, 397-406.

[21] Fernández-Arroyo S, Rodríguez-Medina I C, Beltrán-Debón R, Pasini F, Joven J, Micol V, Segura-Carretero A, Fernández G. 2011. Quantification of the polyphenolic faction and in vitro antioxidant and in vivo antihyperlipemic activities of Hibiscus sabdariffa aqueous extract. Food Rese.Inter. 44 (5): 1490-1495.

[22] Falade OS, Otemuyiwa A, Oladipo O, Oyedapo BA, Akinpelu, Adewusi S R. 2005. The chemical composition and membrane stability activity of some herbs used in local therapy for anemia. J. Ethnoph. 102: 15-22.

[23] Ali BH, Al Wabel N, Blunden G. 2005. Phytochemical, pharmacological and toxicological aspects of Hibiscus sabdariffa L.: A rev.. Phyto. Res., 19(5), 369-375.

[24] Gradinaru G, Biliaderis C G, Kallithraka S, Kefalas P, GarciaViguera C. 2003. Thermal stability of Hibiscus sabdariffa L. anthocyanins in solution and in solid state: effects of copigmentation and glass transition. Food. Chem. 83(3), 423-36.

[25] Maganha EG, Halmenschlager R D, Rosa R M, Henriques J A P, Ramos A, Saffi J. 2010. Pharmacological evidences for the extracts and secondary metabolites from plants of the genus Hibiscus. Food Chem. 118(1), 1-10.

[26] Zilic S, Serpen A, Akıllıglu G, Jankovic M, Gökmen V. 2012. Distributions of phenolic compounds, yellow pigments and oxidative enzymes in wheat grains and their relation to antioxidant capacity of bran and debranned flour. J. of Cerl. Scie.. 56:652-658.

[27] Hwang ES, Do Thi N. 2014. Effects of Extraction and Processing Methods on Antioxidant Compound Contents and Radical Scavenging Activities of Laver (Porphyra tenera). Prev. Nutr. Food Sci.19:40-48. 
[28] Khoshnam FB, Zargar N, Pourreza H. 2010. Aceton extraction and HPLC declaration of acrylamide in potato chips. J. Iran. Chem. Soc., 7: 853-858.

[29] Babalola SO, Babalola AO, Aworh OC. 2001. Compositional attributes of the calyces of roselle (Hibiscus sabdariffa). $J$. Food Technol. Afr. 6 (4), 133-134.

[30] Wong PK, Yusof S, Ghazali HM, Che Man YB, 2002. Physicochemical characteristics of roselle (Hibiscus sabdariffa L.). Nutr. Food Sci. 32, 68-73.

[31] Anokwuru CP, Esiaba I, Ajibaye O, Adesuyi AO. 2011. Polyphenolic content and antioxidant activity of Hibiscus sabdariffa calyx. Res. J. of Med. Pla.5(5):557-566.

[32] Obouayeba AP, Djyh NB, Diabate S, Djaman AJ, N'guessan Jean D, Kone M, Kouakou KH. 2014. Phytochemical and antioxidant activity of roselle (hibiscus sabdariffa 1.) petal extracts. Res. J. of Pharm., Biolo. and Chem.Scien.5 (2) 1453-1465.
[33] Cheng K, Zeng K, Tang Y, Wu J, Liu Z, Sze K. 2009. Inhibitory mechanism of naringenin against carcinogenic acrylamide formation and nonenzymatic browning in Maillard model reactions. Chem. Res. in Toxic. 22, 1483148.

[34] Bunger A, Moyano P C, Roseco,V K. (2003). NaCl soaking treatment for improving the quality of French-fried potatoes. Food Research International, 36, 161-166.

[35] Franke K, Sel M, Reimerdes EH.(2005). Quality related minimization of acrylamide formation - An integrated approach. In Chemistry and Safety of Acrylamide in Food. M. Friedman \& D. Mottram, Eds.: 357-369. Springer. New York, NY.

[36] Haase NU, Matthäus B, Vosmann K.(2003). Acrylamide formation in foodstuffs - Minimising strategies for potato crisps. Deut Lebensm - Rundsch ;99:87-90. 